\title{
La violencia policial como "mensaje": un abordaje desde la experiencia de jóvenes de Latinoamérica
}

\author{
MARIANA JÉSICA LERCHUNDI*
}

Artículo de investigación sobre las políticas de seguridad y las violencias policiales desplegadas sobre jóvenes latinoamericanos.

Recibido: 5 de febrero del 2020 - Evaluado: 5 de abril del 2020 - Aceptado: 24 de abril del 2020

Citar como: Lerchundi, M. J. (2020). La violencia policial como "mensaje": un abordaje desde la experiencia de jóvenes de Latinoamérica. Hallazgos, 17(34), 23-54. DOI: https://doi.org/10.15332/ 2422409X.5488

Doctora en Administración y Política Pública, Conicet-Universidad Nacional de Río Cuarto (UNRC), Argentina.

Correo electrónico: marianalerchundi@gmail.com

ORCID: 0000-0002-3767-3917 


\section{Resumen}

Este artículo se ubica en la línea de investigación que busca desentrañar diferentes dimensiones de la violencia policial, entendidas como un efecto de las políticas de seguridad. Aquí se comprende la violencia policial desplegada sobre jóvenes latinoamericanos como un "mensaje”, que se leerá con base en los relatos de los jóvenes víctimas de esas violencias, en dos ciudades latinoamericanas: Río Cuarto (Argentina) y Barranquilla (Colombia). El trabajo se divide en tres apartados, además de la introducción y las conclusiones. En el enfoque teórico se describen las nociones de violencia policial, jóvenes y juvenicidio. En el abordaje metodológico se desliza una síntesis de las decisiones tomadas en el marco del camino investigativo. Posteriormente, se presentan los resultados, primero, a través de una descripción del contexto de las ciudades elegidas, y luego mediante los relatos de los jóvenes. Por último, en las conclusiones se justifica la necesidad de revisar esas prácticas policiales, junto al diseño y la implementación de las políticas de seguridad.

Palabras clave: Argentina, Colombia, jóvenes, juvenicidio, políticas de seguridad, violencia policial. 


\title{
Police violence as a "message": an approach from the experience of young people in Latin America
}

\begin{abstract}
This article is set in the research line that seeks to unravel different dimensions of police violence, understood as an effect of safety policies. Here, the police violence used on Latin American youth is understood as a "message", which will be read based on the stories of the young victims of such violence, in two Latin American cities: Río Cuarto (Argentina) and Barranquilla (Colombia). The work is divided into three sections, besides the introduction and conclusions. In the theoretical approach, the notions of police violence, youth and juvenicide are described. In the methodological approach, a synthesis of the decisions taken within the framework of the research path is made. Subsequently, the results are presented, first, through a description of the context of the chosen cities, and then through the stories of the young people. Finally, the conclusions justify the need to review these police practices, together with the design and implementation of safety policies.
\end{abstract}

Keywords: Argentina, Colombia, youth, juvenicide, safety policies, police violence.

\section{Violência policial como "mensagem": uma abordagem a partir da experiência dos jovens latino-americanos}

\section{Resumo}

Este artigo se encontra no âmbito da linha de pesquisa que pretende esclarecer diferentes dimensões da violência policial entendidas como um efeito das políticas de segurança. Aqui, a violência policial exercida sobre jovens latino-americanos é compreendida como uma "mensagem" que é lida com base nos relatos dos jovens vítimas dessas violências, em duas cidades latino-americanas: Río Cuarto (Argentina) e Barranquilla (Colômbia). Este trabalho está dividido em três seções, além da introdução e das conclusões. Na abordagem teórica, são descritas as noções de "violência policial", “jovens" e "juvenicídio". Na metodológica, é apresentada uma síntese das decisões tomadas no âmbito do caminho investigativo. Em seguida, são expostos os resultados: primeiro, a partir de uma descrição do contexto das cidades selecionadas para o estudo e, logo, dos relatos dos jovens. Por último, nas conclusões, é justificada a necessidade de repensar essas práticas policiais, bem como o desenho e a implementação das políticas de segurança.

Palavras-chave: Argentina, Colômbia, jovens, juvenicídio, políticas de segurança, violência policial. 


\section{Introducción}

El mapa global de la violencia ubica a Latinoamérica como la región más desigual e inequitativa del planeta (Programa de las Naciones Unidas para el Desarrollo [PNUD], 2014). Un informe presentado por la Comisión Interamericana de Derechos Humanos (CIDH) en 2015 expone la preocupación por las condiciones de vida de los jóvenes latinoamericanos, cuyas trayectorias vitales suelen estar atravesadas por situaciones de abuso, violencia y negligencia por parte de los adultos. En el informe se menciona a la institución policial como una de las responsables. También muestra que el común denominador de las políticas de seguridad implementadas por los Estados de la región ha sido el endurecimiento de las penas de privación de libertad, las propuestas de reducción de la edad de responsabilidad penal juvenil y la atribución de nuevas y mayores competencias a las fuerzas de seguridad del Estado. Sobre este último punto, la CIDH agrega que los Estados han llevado sus estrategias hacia una progresiva militarización de la policía y la atribución de competencias en materia de seguridad ciudadana al ejército. Así,

[...] la Comisión muestra su preocupación por las elevadas cifras de detenciones arbitrarias, uso excesivo de la fuerza y de la fuerza letal, tratos crueles, inhumanos y degradantes, ejecuciones extrajudiciales y desapariciones forzadas, así como la lentitud en su investigación y el nivel de impunidad en que quedan estos actos. (CIDH, 2015, p. 15).

La violencia se encuentra sectorizada, especialmente, sobre algunos grupos sociales y etarios. Quienes se encuentran más expuestos a la violencia e inseguridad son las personas entre 15 y 29 años de edad (CIDH, 2015), sobre todo los varones de esa franja etaria. Ellos corren mayores riesgos de ser víctimas de homicidio respecto de otras edades o sexo (Oficina de las Naciones Unidas contra la Droga y el Delito [UNODC], 2019).

En este contexto se ubica nuestra línea de investigación, que se ocupa en desentrañar diferentes dimensiones de la violencia policial, entendidas como un efecto de las políticas de seguridad de nuestros países. Es por ello por lo que en el presente artículo comprendemos la violencia policial desplegada sobre los jóvenes latinoamericanos como un "mensaje”, y se leerá en dos ciudades latinoamericanas: Río Cuarto (Argentina) y Barranquilla (Colombia).

Delinear una pregunta-problema puede conducir a interrogarse sobre el origen del mensaje en el contexto global y latinoamericano, sobre las prácticas de violencia 
policial. Para su análisis es posible retomar el encadenando de diversos episodios que tienen sus antecedentes más visibles en el modelo inquisitorial (Zaffaroni, 2012), con la persecución a los herejes. Ya con el antiguo derecho castellano español, la persecución era destinada a ciertos sectores identificados como "vagos" y "malentretenidos" (Barzola, 2016); con el transcurso del tiempo se fue ajustando a los miedos y prejuicios construidos por cada sociedad, que hoy tienen como foco a los jóvenes de sectores populares.

Otra posibilidad para elaborar una pregunta-problema es retomar el camino recorrido por Valenzuela Arce (2019), quien encuentra algunas interpretaciones posibles en el propio sistema capitalista. Así, este autor, que ha fundado la noción de juvenicidio para explicar la muerte de jóvenes en la región, vuelve a Marx (2014) para decir que el capital nace con el despliegue de violencia, con "trazos indelebles de sangre y fuego" (p. 103).

El autor entiende que "los discursos que conlleva el despliegue de muerte artera y cuerpos supliciados” (Valenzuela Arce, 2019, p. 23), los necrodiscursos, suelen acompañar los cadáveres en textos inscritos en cartulinas, hojas de papel, mantas o la superficie epidérmica, donde se escribe el "mensaje”. Pero en otras ocasiones, al igual que Segato (2016), entiende que el propio cuerpo es el "mensaje” que busca amedrentar, intimidar, infundir miedo, retraer la acción y la resistencia social.

Valenzuela Arce (2019) habla de las prácticas que atraviesan al mensaje. Se detiene en aquellas ocurridas en México; las prácticas crueles son grabadas en la intimidad de los sitios de exterminio ${ }^{1}$ y difundidas gracias a internet. Los videos muestran diversas performance desplegadas por los grupos tras la exhibición del suplicio (Valenzuela Arce, 2019, p. 26). Los discursos de la muerte, las prácticas de violencia, asumen diversas formas en la región; sin embargo, esa variabilidad se tiñe del mismo color opaco: el de la impunidad.

Ahora bien, ¿cuál es el "mensaje” que se construye y se transmite en el ejercicio de la violencia policial? ¿A quiénes va dirigido ese "mensaje”? ¿Cuál es el código y el contexto de ese “mensaje”? ¿Dónde se escribe ese “mensaje”? ¿Qué ocurre en Río Cuarto y Barranquilla? Estas preguntas ayudan a deslindar algunas dimensiones

1 Agradecemos este aporte a la militante mexicana de derechos humanos que busca a sus familiares desaparecidos, Graciela Pérez, fundadora de Milinary Red CFC A. C., quien nos enseñó que nombrar esos espacios como "cocinas” es sostener la categoría nativa de los criminales. Las organizaciones prefieren señalarlos como "sitios de exterminio". 
posibles para el análisis de la violencia policial en los jóvenes de sectores populares de estos territorios.

El presente artículo se estructura en tres apartados, más la introducción y las conclusiones. En el primero de ellos se describen los principales referentes teóricos que permiten construir el marco de interpretación de las experiencias analizadas, inscritas en un clima de violencia e inseguridad. Este acápite presenta las nociones de violencia policial, jóvenes y juvenicidio. El segundo desliza una síntesis de las decisiones tomadas en el marco del camino investigativo. Propone algunos conceptos de orden teórico, el tipo de muestreo, las técnicas de recolección y análisis de los datos, la conformación del corpus y, fundamentalmente, el acceso al campo y a los escenarios de aplicación de los instrumentos.

En el tercer apartado, en primer lugar, se realiza una contextualización amplia y general de la temática. En segundo lugar, se analizan las entrevistas a jóvenes de las comunidades donde se desarrolló el trabajo de campo, en relación con las prácticas de violencia, los territorios y la afectación a los derechos de los jóvenes, espacio donde el texto y el contexto del "mensaje” de la violencia se toman como ejes de análisis del código.

Finalmente, en las conclusiones se abre un campo de respuestas a los interrogantes iniciales que ponen el eje en las prácticas de violencia policial, en el mensaje que se transmite, a través de su ejercicio, donde se justifica la necesidad de revisar esas prácticas, junto al diseño y la implementación de las políticas de seguridad. En consecuencia, se toma postura frente a las prácticas implementadas y las deseadas, basándonos en la necesidad de establecer un abordaje preventivo e integral del problema, que parta de la protección y el respeto de los derechos humanos. Por último, se abre una línea que conduce a pensar la necesidad de reducir las desigualdades, acerca del crecimiento de la pobreza y la desigualdad endémica y los efectos de la violencia en los contextos habitados por estos jóvenes.

\section{Enfoque teórico y relevancia del juvenicidio para el estudio de la violencia policial}

\section{Violencia policial}

Las investigaciones sobre la agencia policial llegan a los países latinoamericanos en la década de los ochenta, con el regreso de las democracias y la influencia de los estudios norteamericanos y europeos, que previamente realizan algunas aportaciones sobre 
la agencia policial comprendida como objeto de estudio en sí mismo. En el contexto norteamericano y europeo se rescatan las investigaciones de Skolnick (1965), Bittner (1970, 1974), Manning (1991) y Monjardet (2010). Los trabajos de Skolnick y Bittner, como pioneros de los estudios sobre agencia policial, advierten la discrecionalidad de su actividad y reducen a un papel secundario las regulaciones legales que guían en su trabajo cotidiano. Un aporte central de los autores es la actitud de sospecha o táctica de la sospecha que conduce las actuaciones policiales (Skolnick, 1965; Skolnick y Fyfe, 1993). Las investigaciones de Manning y Monjardet cuestionan el trabajo policial en orden a la cotidianeidad, la cultura profesional y la des-homogeneización de la agencia policial, según cada uno de los abordajes. Las producciones referidas brindan una amplia base para investigaciones en la región y su consecuente recepción y producción en toda América Latina.

Para hablar de violencia policial es necesario retomar la noción de monopolio de la fuerza que el Estado detenta y ejerce a través de sus fuerzas de seguridad. Para Jobard (2018) el uso legítimo de la violencia es su uso legal. Así, violencia policial abarca aquellas situaciones definidas por ley como "uso policial de la fuerza", casos no siempre claros que trasuntan en la ambigüedad e interpretación de cada agente policial. El autor describe tres situaciones. La primera es el uso de la fuerza cuando el policía esté bajo amenaza de una violencia real e inmediata, por lo que debe aplicarse el principio jurídico de razonabilidad, es decir, la proporcionalidad del daño. La segunda sucede cuando el agente de policía debe aprehender o arrestar a una persona, donde menciona la limitación del uso letal de la fuerza; en este caso también operan la razonabilidad y la proporcionalidad. La tercera supone una orden de mayor jerarquía, ajustada a la Declaración Internacional de los Derechos Humanos.

Si bien las actuaciones de las fuerzas de seguridad están —-deberían estarreguladas por leyes, los agentes también adoptan recursos no contractuales (Monjardet, 2010). Por ejemplo, las escuchas secretas o el tráfico de información son propios de la policía de información; sin embargo, otras actuaciones como la presencia de policías de civil y las operaciones encubiertas también son adoptadas por la policía de seguridad, con lo cual se configura, de ese modo, un espacio opaco donde sus prácticas se despliegan. Por lo tanto, no son claramente distinguibles como legales o ilegales (Brodeur, 2011). La fuerza pública termina materializándose en la figura del policía (Manning, 2011), y su monopolio, dice Brodeur (2011), es una ficción.

Jobard (2018) enuncia una serie de características que deberían hallarse en una práctica policial para comprender que es ilegítima y, por tanto, violenta. El autor entiende que el primer elemento es el uso excesivo de la fuerza, es decir, tiene que 
ser notable y gravemente desproporcional al motivo de la intervención policial. El segundo elemento es el contexto del uso de la fuerza, lo cual implicaría que el policía actuó sin estar bajo peligro o amenazado. El tercer elemento es la evidencia; el autor propone que la víctima de abuso policial debe tener pruebas técnicas que sostengan sus declaraciones, como informes médicos o videos.

Desde nuestra postura entendemos que el tercer elemento reviste de dos vicios que impide ser cumplimentado. Si bien resulta más favorable aportar pruebas materiales y no solo el testimonio de la víctima, no es sencillo cuando los abusos ocurren sin testigos o, por ejemplo, las golpizas no dejan rastros en el cuerpo, como mostraremos en el tercer apartado. Además, la violencia policial no puede ni debe ser registrada solo desde las marcas físicas; por el contrario, como hemos escrito en otros textos, la violencia subjetiva es igualmente grave (Lerchundi y Bonvillani, 2014; Lerchundi, 2018).

El cuarto elemento se refiere a la nulidad de antecedentes en el expediente de la víctima, es decir, sería "más válida” una experiencia de alguien que es violentado por primera vez por la policía. Sin embargo, coincidimos con Jobard (2018) cuando habla de las víctimas de violencia policial como parte de una suerte de clientèle penal (p. 4), esto es, grupo de sujetos seleccionados por la cadena punitiva que son detenidos una y otra vez, lo que afecta no solo a las víctimas, comprendidas por el autor como poblaciones manchadas, sino también a sus familias, amigos y entorno social.

Continuando con el estado del arte de los estudios sobre policía, en el contexto latinoamericano recientemente las investigaciones sobre agencia policial se han cuestionado los modos de actuación de las instituciones, las reformas policiales y las nuevas tendencias sobre esta materia (Binder y Martínez, 1998; Waldmann, 2003; Dammert, 2003, 2005; Vargas Velásquez, 2012). Otros trabajos han abordado el accionar policial poniéndolo en tensión con las legalidades y los derechos humanos. Entre estos se encuentran las investigaciones de Tiscornia (2004), Sozzo (2000), Galvani (2007), Frederic (2009), Saín (1998, 2008), Sirimarco (2009), Garriga Zucal y Melotto (2013).

Ahora bien, ¿a qué llamamos violencia policial? Algunos autores (Tiscornia, 2000; Garriga Zucal, 2016) entienden que aquello que se comprende como violencia no es más que el resultado de un conjunto de relaciones sociales ubicadas en un espacio y tiempo determinados; por tanto, un acto entendido como violento es siempre una disputa por su sentido. Propone Seguezzo (2010) "la 'violencia' es presentada como una práctica, un mecanismo, cuyo carácter y efecto es únicamente represivo (cercena y reprime la vida) y no productivo, un modo de constitución de las 
subjetividades" (p. 8). Apoyados en esta noción, que complementa la propuesta de Jobard (2018), nos servimos de estas herramientas para el análisis de nuestro corpus de entrevistas, como se verá en el tercer apartado.

\section{Jóvenes}

¿A qué nos referimos con juventudes y con jóvenes? La juventud" es una "clase" de edad, una categoría, mientras que jóvenes son los sujetos que la componen, es decir, personas concretas que sienten, piensan y actúan. La clasificación por edad, dice Bourdieu (2002), es una forma de limitar las categorías. En ese sentido, Filardo (2018) propone que la edad es un dispositivo rígido y universal, generalmente medido en años como escala única del tiempo vivido. Habla de una edad cronológica a la que, producto de una construcción sociocultural, se le asignan roles, mandatos y significados. Sin embargo, por medio de esa definición no se acota la juventud, en tanto categoría, a nociones esencialistas, sino que propone la existencia de distintas edades: cronológica, biológica, social, subjetiva, burocrática e histórica. La autora profundiza la perspectiva que Bourdieu (2002) inaugura al enunciar la complejidad que se abre entre la edad social y la biológica.

Así, respecto de la primera, entiende que la edad cronológica es el tiempo transcurrido desde el nacimiento, el cual no se corresponde con un tiempo biográfico universal, pero cuantifica las trayectorias individuales a lo largo del ciclo vital. La edad biológica es la que se corresponde con el paso del tiempo en el cuerpo. Aclara Filardo (2018) que aun con variaciones genitales o medioambientales es idéntica para todas las personas. Por otra parte, la edad social se encuentra caracterizada por las normas, los mandatos y los roles referidos antes. La edad subjetiva implica la autopercepción de cada persona, regulada y negociada con la autoimagen. Estas edades cimientan la edad burocrática, aquella que el Estado y las instituciones configuran para adquirir derechos y obligaciones y ser parte de determinadas políticas públicas. Finalmente, la edad histórica es la que permite ubicar en un territorio y en un tiempo dado los condicionamientos de la edad.

Con la tipología descrita, la autora interpela la idea asumida respecto de la mirada biologicista-esencialista para concebir la juventud, a partir de criterios

2 Otros autores comenden que juventud es una construcción social posterior a la Segunda Guerra Mundial (Balardini 2000; Alpízar y Bernal, 2003; Hopenhayn, 2007). Así mismo, otros problematizan la distinción entre juventud y juventudes desarrollada ampliamente por Duarte Quapper (2000). 
etarios, tal como hemos discutido en un artículo anterior (Lerchundi, 2015). Y nos permite incluir la edad como una dimensión central para hablar de juventud, sin perder de vista que mediante la edad cronológica - conocida en otros textos como paradigma sociodemográfico — no pueden ni debe pretenderse un prisma igualador para las trayectorias vitales de los jóvenes. Del modo que la propone Filardo (2018), la edad cronológica se pone en diálogo con la social, la biológica y la subjetiva.

La autora complejiza las miradas asignadas a la edad, entendiendo con otros investigadores (Reguillo, 2012; Krauskopf, 2019) que no es posible referirse a la juventud por fuera de un contexto social, cultural, histórico y político, situado y configurado por condiciones específicas de existencia. Así mismo, tampoco es posible mirarla en abstracto, sino que su condición relacional la atraviesa desde múltiples perspectivas. En este caso, y para los fines del presente artículo, priorizamos la condición relacional del grupo objeto de estudio de jóvenes víctimas de violencia policial, el cual convive con otras violencias, precariedades o conflictividad multiagencial, como hemos llamado en un texto anterior (Lerchundi, 2019).

Los jóvenes cuyas vidas son analizadas en este contexto y en la configuración teórica del juvenicidio se adscriben a condiciones de vida subalternas (Gramsci,1981), nombradas aquí como sectores populares, entendiendo lo popular en pugna con lo hegemónico. En consecuencia, no todos los jóvenes son alcanzados por la persecución policial, estigmatizados o criminalizados. Las trayectorias biográficas de estos jóvenes se traman en contextos de precarización material.

\section{Juvenicidio}

Si se intenta reconstruir la palabra juvenicidio, diremos que juveni- alude a lo juvenil, a la población joven o al sujeto que etariamente es joven, mientras que cualquier diccionario etimológico dirá que el sufijo -cidio proviene del verbo latino caedere que significa 'acción de matar'. El art. 2 de la Convención para la Prevención y la Sanción del Delito de Genocidio (Asamblea General de las Naciones Unidas, 1948) señala:

En la presente Convención, se entiende por genocidio cualquiera de los actos mencionados a continuación, perpetrados con la intención de destruir, total o parcialmente, a un grupo nacional, étnico, racial o religioso, como tal: a) matanza de miembros del grupo; b) lesión grave a la integridad física o mental de los miembros del grupo; c) sometimiento intencional del grupo a condiciones de existencia que hayan de acarrear su destrucción física, total o parcial; d) medidas destinadas a impedir los nacimientos en el seno del grupo; e) traslado por fuerza de niños del grupo a otro grupo. 
La Convención dejó fuera otras formas de eliminación brutal, como los genocidios ideológicos. Por ello se crearon otros mecanismos complementarios, como el método Garzón, aplicado para el caso argentino, que "utilizó como categoría remanente el llamado 'grupo nacional', ya que sería la forma de englobar a las víctimas en un conglomerado general, del que formaban parte y cuya estructura identitaria se quiso modificar con el propio proceso genocida" (Bailone, 2016, p. 64). En esta línea, Fefferman (2015) — también Rangel y Alves Oliveira (2015) — entiende que la violencia acaecida en Brasil es un genocidio de la juventud afrobrasileña, exterminio masivo sin guerra. Identifica a los jóvenes negros como el enemigo interno, chivo expiatorio de esa violencia institucional.

Los autores que promueven la noción de juvenicidio hablan de una

[...] limpieza social de jóvenes pobres, favelados, indígenas, afrodescendientes en Brasil; los falsos positivos en Colombia; la agresión contra integrantes de barrios y pandillas como ocurre en la Mara Salva Trucha y el Barrio 18 en Estados Unidos, Guatemala, El Salvador y Honduras; las víctimas del feminicidio, así como la guerra contra el crimen organizado en México, puntualmente en los sucesos de Iguala, Guerrero. (El Colef, 2017, s. p.) $)^{3}$

Los ejemplos mencionados por El Colef: ¿pueden ser pensados como grupo nacional, étnico, racial o religioso, como lo indica la Convención, o grupo ideológico, como señala el método Garzón? Una respuesta rápida nos invitaría a profundizar en la perspectiva que apenas menciona Bailone (2016): la estrategia de algunos sociólogos del genocidio que sugieren mirar ex post facto y analizar la intención del sujeto organizador del genocidio.

Muchos de los jóvenes argentinos que ingresan a la cadena punitiva (López, Guemureman y Bouilly, 2012) a través de las prácticas de interceptación policial (Lerchundi, 2018) luego son asesinados por gatillo fácil (Llobet, 2015), pierden sus vidas en manos de las fuerzas de seguridad. Los falsos positivos de Colombia responden a desapariciones seguidas de muertes contadas como fusilamientos en combate a miembros de la guerrilla. La muerte de niños y jóvenes favelados en Río de Janeiro ocurre por la policía o el narcotráfico. Entonces: ¿podemos hablar de esas muertes sistemáticas de cuerpos jóvenes como un genocidio, como un juvenicidio que en cada país asume prácticas juvenicidas propias?

3 Fragmento hallado en la página de El Colef (El Colegio de la Frontera Norte de México) para difundir el Diplomado "Juvenicidio y vidas precarias en América Latina”. 
La necesidad de poner en palabras la violencia y la muerte hizo que, en Estados Unidos, en la década de los setenta del siglo xx, Diana Russell planteara la idea de femicide $^{4}$, reinterpretada en América Latina comofemicidio y feminicidio, para nombrar las muertes de mujeres y cuerpos feminizados, consecuencia del poder y la desigualdad de género. Esta misma necesidad hizo que investigadores de la región fundaran la noción de juvenicidio para nombrar las muertes físicas y simbólicas de los jóvenes. Valenzuela Arce (2015) sostiene que "juvenicidio alude a la condición límite en la cual se asesina a sectores o grupos específicos de la población joven” (p. 15). Esa categoría es señalada por primera vez por el autor en 2012, en el libro Sed de mal: femicidio, jóvenes y exclusión social. Como escribió Reguillo (2013), la noción representaba los procesos violentos y las altas tasas de mortalidad juvenil. Sin embargo, los hechos de Ayotzinapa, en 2014, en Iguala, México, con la desaparición forzada de 43 estudiantes normalistas, exigieron una ampliación de la categoría, que pretendía iluminar ahora mucho más que la eliminación brutal de los cuerpos jóvenes. Puso en visibilidad las trayectorias vitales precarias de la población joven en Latinoamérica.

En este contexto prevalecen formas de vivir y de morir, modos de nombrar y de extranjerizar la cotidiana repetición de las escenas de violencia que, como indica Segato (2016), producen un efecto normalizador. Aquíi impera un mensaje de crueldad que sumerge a la ciudadanía a bajos umbrales de empatía, condición indispensable para la empresa depredadora de la violencia. El poder patriarcal, extractivista y colonial sobre los cuerpos hace que tanto el femicidio como el juvenicidio representen síntomas de condiciones estructurales más amplias que los incluyen. Los discursos hegemónicos y las industrias culturales estereotipan conductas y estilos juveniles descalificables, respecto de los cuales disminuye la empatía social. Sus vidas les son arrebatadas debido a los contextos de precarización, vulnerabilidad, estigmatización y criminalización, que en muchos casos llegan a la muerte.

La noción de juvenicidio es una apuesta académica y política con potencia jurídica. Su significado no aparece en el diccionario como tampoco en nuestras legislaciones. Sus referentes teóricos apuntan el poder heurístico del concepto, es decir, su potencialidad para describir escenarios de precarización y violencia e inscribir la vida de los jóvenes en contextos de corrupción e impunidad, que amplían las

4 La categoría, de origen americano, es repensada en el contexto latinoamericano, a partir de los feminicidios acaecidos en Ciudad Juárez, México, ocurridos desde 2010, con la llamada "Guerra contra el Narcotráfico” de Felipe Calderón. Para el caso argentino, la misma categoría asume el nombre de feminicidios. 
condiciones de vulnerabilidad e indefensión de estos grupos subalternizados a partir de ordenamientos sociales, racistas y de orden prohibicionista. En ese sentido, el concepto se refiere tanto a la eliminación física de la vida de los jóvenes como al proceso de consolidación de dispositivos que los ubican en condiciones estructurales de precarización y vulnerabilidad (Valenzuela Arce, 2015, 2019; Nateras, 2015; Valenzuela Arce y Morañas, 2017).

Los escenarios precarios amplían las interpretaciones del juvenicidio ya no solo destinado a explicar la eliminación de los cuerpos jóvenes, sino a otras esferas como la económica, la social o la cultural ${ }^{5}$. Se habla así de 1) violencia económica para indicar la imposibilidad de cubrir una canasta básica de alimentos; 2) violencia institucional ${ }^{6}$ para referir los modos de estigmatización y criminalización de las juventudes y el control ejercido sobre sus cuerpos (sexualidad, prohibición del aborto, etc.); 3) violencia social expresada a través de los marcos prohibicionistas; 4) violencia barrial que confronta a jóvenes entre sí y se liga a la violencia simbólica y a la discriminatoria (Valenzuela Arce, 2019).

Finalmente, cabe subrayar, junto a Valenzuela Arce (2019), que "el juvenicidio implica una responsabilidad de Estado como garante de la seguridad de la ciudadanía, además de que existe participación y responsabilidad directa de figuras de Estado en la muerte persistente y sistemática de jóvenes latinoamericanos” (p. 64). Es por esta razón por la que nos resulta central comprender la violencia policial en el marco del juvenicidio.

\section{Enfoque metodológico e ingreso al campo}

El presente artículo se inscribe en la trayectoria de investigación constructivista y cualitativa (Guba y Lincoln, 1994). Se tomarán como corpus de análisis las entrevistas realizadas a jóvenes, varones y mujeres, de sectores populares de Río Cuarto y Barranquilla. Así mismo, se añade el resultado de unos talleres sobre violencia policial desarrollados en una institución educativa riocuartense. El trabajo de campo reunido en

5 Valenzuela Arce (2012) identifica 10 tipos de violencia, en relación con la población joven; en este caso se enuncian las más relevantes para poner en contexto la precariedad que atraviesa el sector.

6 En Argentina, violencia institucional es una categoría producida para explicar la violencia policial posterior a la última dictadura cívico-militar. Se recomienda leer Tiscornia (2017) y Pita (2017). 
este artículo se desarrolló en septiembre y octubre de 2019, en Río Cuarto, y en julio y agosto de 2018, en Barranquilla ${ }^{7}$. En este caso, no se prioriza analizar las trayectorias biográficas de los entrevistados ${ }^{8}$; por el contrario, se toman los relatos como texto y se da centralidad en la estructura más que al sujeto.

En lo que respecta a la técnica de análisis se utilizó el análisis de documentos propuesto por Valles (1999), la cual ha permitido hallar denominadores comunes en los que se evidencian las prácticas policiales en ambas territorialidades. De este modo, la búsqueda de regularidades habilitó la problematización de la violencia policial como mensaje, cuestionando el texto, el contexto y, especialmente, el destinatario del mensaje.

El tipo de acceso al campo ha configurado los escenarios de entrevista en cada uno de los casos. Por eso preferimos indicar las posibilidades y las limitaciones de cada uno de ellos. Dividimos el trabajo de campo realizado en dos grandes territorialidades, correspondientes a las ciudades de estudio: Río Cuarto y Barranquilla (tabla 1).

Tabla 1. Descripción del trabajo de campo

\begin{tabular}{|c|c|c|}
\hline \multicolumn{3}{|c|}{ Trabajo de campo } \\
\hline Ciudad & Vía de acceso al campo & Entrevistados $^{*}$ \\
\hline Río Cuarto (2019) & $\begin{array}{l}\text { A través de la Marcha de } \\
\text { la Gorra }\end{array}$ & $\begin{array}{l}\text { Cinco jóvenes varones que asisten a un pro- } \\
\text { grama nacional sobre consumos problemáti- } \\
\text { cos, en el barrio Amancay. } \\
\text { Tres jóvenes mujeres, militantes de derechos } \\
\text { de las mujeres. } \\
\text { Veinte jóvenes, tanto varones como mujeres, } \\
\text { de la Institución Educativa Champaquí. }\end{array}$ \\
\hline Barranquilla (2018) & $\begin{array}{l}\text { A través de un activista } \\
\text { joven }\end{array}$ & $\begin{array}{l}\text { Seis jóvenes, varones, que viven en el barrio } \\
\text { Lemu, de Barranquilla. }\end{array}$ \\
\hline
\end{tabular}

* Los nombres de instituciones, barrios y otros no son reales; los originales se remplazan por nombres de pueblos originarios argentinos.

Fuente: elaboración propia con base en el trabajo de campo efectuado.

7 Los trabajos de campo se ubican en el marco de una Beca Postdoctoral de Conicet (2017-2020), para Río Cuarto, y una Beca de Integración Regional del Ministerio de Educación, Cultura, Ciencia y Tecnología de la Nación (2018), para Barranquilla.

8 En otros artículos hemos analizado trayectorias biográficas, en trabajos de campo sobre violencia policial y detenciones arbitrarias. Al respecto se recomienda consultar los estudios de Lerchundi y Bonvillani (2014) y Lerchundi (2019). 
Como se detalla en la tabla 1, en Río Cuarto el acceso al campo ha sido a partir de la Marcha de la Gorra. Al tener ese espacio colectivo, un posicionamiento público y activo respecto de la política de seguridad y la violencia policial habilitó una interacción fluida con las personas entrevistadas. Las conversaciones tuvieron lugar, en el primer caso, en un dispensario donde se implementa una política pública nacional, cuyos destinatarios son jóvenes con consumos problemáticos. La confianza existente con los adultos del equipo de trabajo contribuyó a describir y explicar las experiencias de violencia policial que estos jóvenes atravesaron. En el segundo caso, la entrevista a jóvenes militantes tuvo lugar en la casa de una de ellas. Finalmente, el tercer caso refiere a unos talleres sobre violencia policial desarrollados en una institución educativa.

En Barranquilla, para los fines de este artículo, se retoma el trabajo de campo llevado a cabo en el barrio Lemu, donde asistimos con un activista joven a dicha comunidad. En las entrevistas semiestructuradas (Flick, 2007) se pudo ahondar en torno a la violencia policial en sus diversas manifestaciones.

El acceso al campo fue conducido por un muestreo de tipo intencional (Sautu, 2003), es decir, generado por la accesibilidad al territorio y en razón de las pretensiones de la investigación. En consecuencia, estos acercamientos representan una foto de esas comunidades, configuradas según las interacciones indicadas, mas no es posible una generalización de los resultados.

\section{Construcción de resultados}

\section{Contexto: una región, dos ciudades}

Nos preguntamos antes: ¿cuál es el contexto del mensaje de la violencia? El Informe sobre Desarrollo Humano 2019 y las desigualdades en el siglo XXI (PNUD, 2019) indica que Argentina se ubica en el puesto número 48 , con un índice de 0,83 , considerado un desarrollo humano muy alto. Si contamos los países latinoamericanos, Argentina se ubica en el segundo lugar, después de Chile. Mientras que Colombia se encuentra en el puesto número 79, con un índice de 0,76 , comprendido como un desarrollo humano alto. Si se toman como contexto los países latinoamericanos, se ubica en el puesto número 10, junto a Brasil.

Sin embargo, y a pesar de los buenos indicadores sobre desarrollo humano de estos países, la región de América Latina y el Caribe presenta los mayores índices de violencia y la tasa de homicidio en relación con los habitantes más alta del globo 
(PNUD, 2014). Los hechos de violencia letal varían según la región y confluyen múltiples variables. En Río Cuarto, en 2019, hubo 14 homicidios violentos, lo que representa una tasa de 8,5 personas muertas por cada 100.000 habitantes (Telediario. com.ar, 2 de diciembre de 2019). La cifra no tiene precedentes para la ciudad ubicada en la provincia de Córdoba, donde el acceso a bienes y servicios es superior respecto de otros distritos del país. Por su parte, Barranquilla, ciudad del departamento del Atlántico, en 2018 presentó 311 homicidios, una tasa de 25,4 personas por cada 100.000 habitantes, número inferior respecto de los indicadores anteriores (Navarro y Pérez, 14 de enero de 2019), pero muy alta en lo que respecta a la región. Es decir, Barranquilla triplica la tasa de homicidios que fueron récord para la ciudad argentina objeto de estudio, lo que ya indica una diferencia entre ellas respecto de la conflictividad.

Las políticas de seguridad de ambos países y ciudades tienen algunas diferencias sustanciales. Por ejemplo, en el caso de Argentina, por la característica federal de su país, las decisiones que más afectan a la población objeto de estudio dependen del nivel subnacional de la provincia de Córdoba, que es la encargada de coordinar y disponer sobre los delitos y contravenciones en ese distrito. Mientras que el Estado local y nacional no tienen efectos sustanciales en esa materia, salvo los delitos de orden federal y algunas faltas que son gestionadas por los municipios.

La diferencia en ese punto es marcada para Colombia, por su característica de país unitario. Las decisiones en materia de delitos y contravenciones dependen del Estado nacional a lo largo de todo el territorio. Esto supone que si bien Barranquilla, por ser una ciudad caribeña no se encuentra directamente afectada por el conflicto armado, la normativa (Código de Policía), junto al entrenamiento y el conocimiento de sus fuerzas de seguridad, es idéntica para cualquier parte del territorio colombiano, por lo que puede advertirse cierta militarización de la policía, tal como se indicaba en la introducción. Las fuerzas de seguridad de ese país trabajan mediante un modelo que divide la ciudad en sectores (cuadrantes). Siguiendo su ejemplo, el modelo fue introducido en la provincia de Córdoba, que desde hace décadas viene copiando las reformas securitarias colombianas y aplicándolas a esta región argentina.

A pesar de las diferencias entre ambas ciudades, marcadas por la violencia traducida en muertes, por los habitantes que concentra cada una de las urbes, por sus prácticas culturales y sociales, por las diferencias administrativas y jurídicas, lo que las une son las políticas de seguridad de corte punitivo y represivo. El modelo copiado por Córdoba a Colombia trabaja con base en las nociones propuestas por el paradigma de la seguridad ciudadana (García Pulgarín, 2012), encargada de prevenir 
el delito, a través de la persecución de colectivos específicos como son los jóvenes de sectores populares. Podemos decir, junto a Fefferman (2015), y retomando la categoría de Wacquant (2004), que el Estado penal, tras el deterioro del Estado de derecho, implementa políticas punitivas y controla la población debido al miedo y la inseguridad. En los párrafos que siguen describimos algunas dimensiones en torno a la violencia policial en jóvenes, en la voz de los miembros de las comunidades donde el mensaje de la violencia se despliega; especialmente, reparamos en el mensaje y el destinatario del mensaje de la violencia.

\section{Jóvenes y el mensaje de la violencia}

Nos preguntamos antes: ¿cuál es el "mensaje” que se construye y se transmite en el ejercicio de la violencia policial? ¿A quiénes va dirigido ese "mensaje”? ¿Cuál es el código? ¿Dónde se escribe ese "mensaje”? ¿Qué ocurre en Río Cuarto y Barranquilla? A continuación, se configuran algunos destinatarios del mensaje, estrategia organizadora de este acápite, que expone experiencias de detención y relatos en torno a la violencia policial de los jóvenes de ambas ciudades.

\section{Mensaje para la institución}

La violencia policial reporta el ejercicio de un tipo de violencia que debe responder a los elementos propuestos por Jobard (2018). Se ejerce en condiciones desiguales: por un lado, se encuentra el policía, representante del Estado, y como tal quien detenta del monopolio de la fuerza, el uso legal y hasta ilegal pero legítimo de ella; por el otro, los jóvenes desprovistos de esos privilegios. Ahora bien, además de los dos extremos existen otros actores que pueden ser parte del contexto, ya sea como testigos, esto es, personas que eventualmente se encuentran en el escenario donde la violencia se despliega, u otros actores no presentes, es decir, que no participan, pero son también destinatarios del mensaje.

En este caso, se prioriza la mirada activa de los "colegas" que forman parte de la “institución policial”. Dada la verticalidad que la atraviesa, la violencia desplegada por un policía recibe la evaluación de sus pares y, sobre todo, de sus superiores, quienes a partir del cumplimiento de cierta normativa formal e informal se asignan adicionales, bonificaciones o días de descanso. Veamos los casos que siguen. Se retoman tres fragmentos de entrevistas. El primero de ellos describe ejemplos de violencia física. El joven dice:

Lo que más se ve es la violencia física de parte de ellos, no sé, porque parece que estuviese mal... si no, maltratan a alguien, porque siempre quieren estar 
maltratando, maltratando, maltratando (entrevista a joven, varón, 6 de julio de 2018, barrio Lemu, Barranquilla).

El joven advierte que la forma regular de relacionamiento de un policía con los jóvenes es de maltrato, que si no existiera un trato violento que medie el vínculo policía-joven pareciera que no obrara con las reglas propias de la institución. ¿Por qué el maltrato? ¿Para quién es relevante ese maltrato? Para los observadores externos del uso de esa violencia.

Otro fragmento de entrevista retrata una demora en la vía pública a un joven riocuartense. Describe cómo el policía hace uso de la tecnología para registrar su imagen. El diálogo procede del siguiente modo:

E: Y cuándo a vos te frenaron, ¿qué te dijeron?

B: Nada. Me sacaron fotos y me pidieron nombre.

E: ¿Te sacaron fotos?, ¿con los teléfonos?

B: Sí, y me dice: “dame todo”. Le di el DNI, 17 AÑos, ADÓNDE VIVÍA, TODO.

E: ¿TE PIDIÓ PERMISO PARA SACARTE LA FOTO?

B: La sacaron así. Ponele que estás ahí frenada, así y uno te habla y el otro viene y te saca. Así te hacen (entrevista a joven, varón, 3 de octubre de 2019, barrio Amancay, Río Cuarto).

En esta ocasión se evidencia la ilegalidad del procedimiento. Las fotos tomadas ingresan a un grupo de WhatsApp de la Policía de la provincia de Córdoba, que si bien puede ser el almacenamiento de información laboral, el dispositivo que lo recibe es del ámbito privado del policía y, por tanto, es ilegal el almacenamiento de dicha información. Esto se encuentra amparado jurídicamente por la Constitución de la Nación Argentina, a través de su artículo 43, y por la Ley 25.326 de Protección de Datos Personales. En este ejemplo, el mensaje es para la propia institución. Es tangible en tanto que se registran datos. Sin embargo, también existe un mensaje para el entorno que comienza a comprender que el registro policial ya no es una suerte de fichaje visual para aquel policía que trabaja en la zona (o cuadrante), sino, además, la imagen personal pasa a estar al alcance del resto de los policías de la ciudad.

En el último caso que se retoma en este acápite, se advierte una recurrencia como el anterior. Ahora no es un registro fotográfico, sino fílmico, y el joven argentino lo explica de la siguiente manera:

Filmaron el procedimiento, violento [...] Y después entre ellos se miraban y uno le explicaba, como que estaban... como que habían salido a practicar un procedimiento y te decía que le enseñaba, le enseñaba cómo agarrarlo... Todo delante 
nuestro, acá en la calle. (Entrevista a joven, varón, 3 de octubre de 2019, barrio Amancay, Río Cuarto).

El desarrollo del procedimiento que se describe en el fragmento anterior, además de explicitar que se registraba con el celular a través de audiovideo, da cuenta de que esa demora policial — requisa en la vía pública — era una suerte de práctica, un entrenamiento acerca del conocimiento que la propia institución provee al policía para una detención. Este fragmento ejemplifica que el mensaje era para la propia institución.

\section{Mensaje para los vecinos}

Los vecinos, a quienes también va destinado el mensaje de la violencia, no siempre son testigos directos de los acontecimientos, como podría advertirse en el último ejemplo propuesto en "mensaje para la institución”, o como resultaría en el que caso que sigue, el cual queda retratado en una conversación en Barranquilla, a saber:

E: ¿Y acá en el barrio hay muchos policías?

J: Sí, aquí bastantes en el barrio. Por ejemplo, aquí hay uno particular que se llama Mano. Que es de apellido Mano, que es uno negrito, que ese pasa... por ejemplo, podemos estar sentados ahí. Y él dice: "vuelvo y paso, y me llevo al que sea para la UPJ". Porque él es él. O a veces estamos sentados por allá arriba, él pasa y como entre, se lleva al primero que esté, al que primero coja se lo lleva. O sea, siempre sin preguntar, sin nada. Él entra, "móntese en la patrulla, y nos fuimos”. O si están ahí todos quietos, ya un carrito, un carrito y llevan [...] los llevan a la UPJ y los sueltan enseguida. O sea, nada más es por llevárselos. (Entrevista a joven, varón, 7 de julio de 2018, barrio Lemu, Barranquilla).

Los jóvenes conocen que ciertos policías que recorren los cuadrantes detienen arbitrariamente. Como se indicó antes, y como surge del trabajo de campo, a cambio los policías pueden recibir ciertos beneficios, por cuanto mayor estadística de detención representaría mejores indicadores de seguridad o reducción de la inseguridad en estos territorios. Así mismo, el joven indica que son algunos espacios del barrio proclives para que ello ocurra. Estar "arriba” puede confirmar una detención policial, caracterizada por subir a varios jóvenes al móvil policial, sin justificativo pero a la luz de la comunidad y con el mensaje claro de que ciertos escenarios, como las

9 Unidad de Prevención y Justicia, desde 2019 lleva el nombre de UCJ. Véase al respecto Alcaldía de Barranquilla (2019). 
esquinas, no pueden ser habitados colectivamente por los jóvenes de sectores populares. Este punto aparece con recurrencia en el trabajo de campo, tanto para Barranquilla como para Río Cuarto. Algunas veces esas detenciones son precedidas por la denuncia de algún vecino que prefiere evacuar la zona de “pelaos” o "pibes”, como se llama a los jóvenes en ambas ciudades, respectivamente.

En el caso que sigue las entrevistadas describen que previo a la detención grupal, de la cual fueron víctimas, y que se describe en “mensaje para los militantes”, una de sus compañeras había sido demorada y golpeada por la policía, en la vía pública, en una escena espectacularizante:

$\mathrm{E}^{\mathrm{a}}$ : En otra ocasión habían golpeado a una compañera.

$\mathrm{E}^{\mathrm{b}}$ : La habían llevado a pasear por todo Río Cuarto y la habían golpeado.

$E^{a}$ : A ella y a su compañero.

$\mathrm{E}^{\mathrm{a}}$ : La cosa es que se armó como un quilombo ${ }^{10}$ en la vía pública y ahí la agarraron a ella y al pibe [...] la habían golpeado y la habían llevado a pasear por todo Río Cuarto [...]. O sea, sin decirle por qué, ni para qué, para qué los tuvieron ahí a los dos. (Entrevista a jóvenes, mujeres, militantes, 5 de septiembre de 2019, Río Cuarto).

En un texto anterior (Lerchundi, 2018) se describió que las demoras en la vía pública podían ser interpretadas como secuestros, acción tipificada por el Código Penal Argentino y bastas legislaciones latinoamericanas, cuando ocurrieran hechos como los que se relatan: un paseo en patrullero a lo largo de la ciudad sin registro policial que mediara ese procedimiento.

Ahora bien, lo que interesa subrayar en este relato es cómo procede una actuación policial cuando hay una exposición pública de conflicto. Esta - expresada a través de numerosos móviles y efectivos - permite brindar la denominada sensación de seguridad a los vecinos. Al respecto comentaba un joven frente a otra situación del barrio:

Si para una pavada así está el grupo eter... si realmente hay tipos armados y delincuentes ¿quién va a venir, quién va a venir? ¿El Ejército? ¿Quién viene? (Entrevista a joven, varón, 10 de octubre de 2019, barrio Amancay, Río Cuarto).

10 Categoría nativa para indicar "lío". 


\section{Mensaje para los familiares}

Un joven, cuyas experiencias de detención estaban vinculadas a su posición de migrante del interior del país hacia Barranquilla, y el andar/transitar con su primo por la ciudad, indica las formas de violencia que no se dejan ver fácilmente, e incluye en su relato las huellas cuyos efectos son tan profundos como los golpes, por la "impotencia” que generan:

Hay situaciones en las que uno siente impotencia, como para no agrandar las cosas, es mejor dejar decir las cosas así. Yo le hago una pregunta: siendo usted, así sea un policía o no, si alguien agrede a su familia: ¿usted qué siente? ¿Tiene ira? ¿Siente impotencia al saber que no se puede meter ahí? Ahora, estando tú en un $\mathrm{CAI}^{11}$ lleno de policías, y que ves tú cómo le pegan con un bolillo a tu primo y le ponen electricidad ¿qué sentirías? Y si ellos estuvieran en el lugar de nosotros, ¿qué harían? (Entrevista a joven, varón, 11 de julio de 2018, barrio Lemu, Barranquilla).

Son violencias de larga duración, prácticas igualmente mortificantes como las marcas en la piel, pero más duraderas porque suponen la latencia de un no accionar posible, la sujeción a cierta violencia simbólica. El joven denuncia la violencia subjetiva que atraviesa las cotidianeidades y produce efectos en sus trayectorias biográficas. Ahora bien: ¿a quiénes va dirigido ese mensaje? ¿Al joven que recibe las descargas eléctricas? ¿A quién mira (testigo y familiar de la violencia) y no puede actuar? ¿Al resto de los "no presentes" para que este relato se transfiera como mensaje testimonial? Tal vez a todos ellos.

En el segundo fragmento que se expone a continuación, el joven nombra a "su mamá” y el impacto a ella generado a partir de la violencia policial ejercida sobre su cuerpo, con sangre derramada y cicatrices en la piel. Aquí es evidente la potencia del amor de una madre en tensión con el dolor y la experiencia del hijo. ¿A quién sino estaría destinado el mensaje violento en este caso? Hablamos de un joven menor de edad que es retirado por sus familiares.

El mismo día que mi mamá me vio de la palera que yo recibí, o sea, de la golpiza que recibí de los policías ese día, mi mamá se asombró; mi mamá casi se desmaya al verme, lloró y todo de cómo estaba yo todo golpeado, y partido y lleno de sangre por todos lados. Por culpa de ellos y mi mamá me decía: “¿pero quién fue? (Entrevista a joven, varón, 11 de julio de 2018, barrio Lemu, Barranquilla).

11 Dependencia policial. 


\section{Mensaje para otros jóvenes}

El fragmento anterior también puede identificarse con un mensaje destinado a los otros jóvenes, sobre todo menores de edad, una suerte de ejercicio ejemplificador, frente a otros jóvenes no presentes. Dice un joven barranquillero respecto del código del mensaje, es decir, los modos en que el emisor (policía) emite el mensaje de la violencia:

Conocemos casos de jóvenes que les han roto las costillas, jóvenes que les han maltratado, les han lacerado la cara, les han partido la cabeza, los han maltratado de una manera inhumana. (Entrevista a joven, varón, 6 de julio de 2018, barrio Lemu, Barranquilla).

El entrevistado describe la violencia física desplegada sobre los cuerpos de jóvenes de los sectores populares de su comunidad. Menciona las formas que asume esa violencia: “cuerpos lacerados”, es decir, el cuerpo abierto producto de las prácticas violentas, el texto escrito en el cuerpo, el mensaje registrado en la carne viva, como camino prefigurado para otros jóvenes. Esa violencia aparece a temprana edad, emerge para comunicar el mensaje de actuación policial, un encadenamiento que escala hasta llegar a los extremos ${ }^{12}$.

En los fragmentos que siguen se retoman dos indicadores de interceptaciones policiales, cuando los jóvenes eran menores de edad:

Me frenaron, era menor de edad [la policía] puede frenar, pueden requisar, pueden pedir tus datos... y uno nada. (Entrevista a joven, varón, 17 de octubre de 2019, barrio Amancay, Río Cuarto).

Hace una semana acá [...] hay un parque por acá, hay un CAI, en la noche, pusieron unas barandas así. Hicieron un círculo en baranda, y todo el que pasara por ahí, ahí lo metían. Ahí lo metían. Todo el que pasara. Todo el que pasara ¡fum! Lo metían para allá dentro. O sea, todo el que... "entre aquí un momentico", y llamaban a la autoridad y se llevaban al grupo. Ese día llevaron un poco de gente para la UPJ. Hicieron el corralito ahí y van, todo el que llegara se lo llevaban. Se lo llevaban para abajo, un grupo grande [...] puros pelaos jóvenes, desde 14 a 18 son los que más se llevan. (Entrevista a joven, varón, barrio Lemu, Barranquilla).

12 Como se explicó en otros artículos, los jóvenes son mucho más que objetos de la violencia policial, son sujetos de acciones. Por el objetivo de este artículo no nos detendremos en este punto. Para más información véase Lerchundi (2018). 
En las entrevistas a los jóvenes, al consultar cuándo comenzaron a ser detenidos, la respuesta siempre es "cuando era menor". No es casual que un joven de sector popular pueda situar estos episodios de su vida con una categoría jurídica en torno a la mayoría de edad. Pues ese hito burocrático, como indica Filardo (2018) en la primera parte del artículo, configura un escenario de nuevos derechos y obligaciones. Las leyes de protección de los derechos de los jóvenes menores de 18 años edad en estos países son coincidentes en las garantías que portan. Por ejemplo, deben ser retirados de la dependencia policial por un familiar o por su tutor/curador cuando sean detenidos, como queda manifiesto en uno de los testimonios sobre "mensaje para los familiares". En esta oportunidad, en el último fragmento se identifica la figura de “corralito" para nombrar una suerte de perímetro o recinto vallado dentro del cual todas las personas que transitaran la zona, pero en particular los jóvenes entre 14 y 18 años, eran privados de su libertad de manera arbitraria. Aquí entendemos, en principio, que la detención masiva envía un mensaje rápidamente a quien podría ser un potencial detenido: "no salgas de tu casa", una alarma que suena para avisar algo que está sucediendo en el cuadrante.

En el caso de esta subcategoría, las voces que se recuperan son de jóvenes varones de sectores populares. Por tanto, no hay que perder de vista que la selección inicial de la policía, la clientèle penal (Jobard, 2018), que comienza cuando son menores de edad, también encubre dimensiones atinentes a un tipo de masculinidad hegemónica, donde resistir, activar, enfrentarse a la policía, configura prestigios territoriales ${ }^{13}$.

\section{Mensaje para los militantes}

En esta última subcategoría se retoman dos fragmentos de jóvenes, mujeres, militantes en materia de género y derechos de las mujeres, en Río Cuarto. La entrevista, en ese caso, tiene como eje de la narración la detención a ellas. En el primero de los fragmentos, la joven describe la cantidad de móviles policiales y agentes de policía que la interceptaron en las calles en una detención grupal.

Los patrulleros eran tres, tres patrulleros y una chata. Ahora, las personas, yo recuerdo de seis. No sé si habrán... sí, había más después porque cuando llegaron los compañeros a preguntar qué había pasado y demás, ahí estaban otros más. Eran muchos. (Entrevista a joven, mujer, militante, 5 de septiembre de 2019, Río Cuarto).

13 Sobre este punto, véase Cozzi (2016). 
Las circunstancias que rodean el hecho, el contexto de la detención, suceden en el centro de la ciudad, luego de una masiva movilización de mujeres. Las jóvenes llegan a sus casas y describen que luego salen a comprar comida y allí son interceptadas por los móviles policiales (patrulleros) y por los policías, quienes las privaron de su libertad por varias horas, con un impacto público y mediático que recorrió los portales de noticias locales y convocó a numerosos activistas sociales a la espera de su liberación. Entonces: ¿a quién va dirigido el mensaje? Las jóvenes y las organizaciones sociales de la localidad la entienden como un caso de criminalización de la protesta social. Un mensaje destinado a otros militantes, una advertencia para el resto de los marchantes.

En otro fragmento, las jóvenes describen un episodio en el que la detención a una de sus compañeras era precedida por otra detención:

$\mathrm{E}^{1}$ : A (una compañera), por ejemplo, la tenían fichada.

$\mathrm{E}^{2}$ : por la otra vez que la habían detenido.

$\mathrm{E}^{1}$ : claro, entonces como que... cuando los agarraron le decían a ella: "dejá de hacerte la revolucionaria”. Como que el milico la reconocía a ella. (Entrevista a jóvenes, mujeres, militantes, 5 de septiembre de 2019, Río Cuarto)

En este caso no queremos señalar solo la cadena punitiva a la que nos referimos en la primera parte de este texto, sino que fundamentalmente pretendemos subrayar el comentario del agente policial al decir "dejá de hacerte la revolucionaria”. El reclamo por los derechos, y en específico de las mujeres y los cuerpos feminizados que se movilizaron ese día, llevó a pensar al policía que había ciertas personas que querían hacer "la revolución”. En Argentina ese significante nos conduce a enlazar la violencia policial con los tiempos más oscuros de la historia reciente de nuestro país: la última dictadura cívico-militar, en la que esos mensajes desembocaban en la desaparición forzada de personas. Dicho comentario no es azaroso, y se convierte en un mensaje para el resto de los militantes, tanto presentes como ausentes.

\section{¿Cuál es el mensaje?}

En este último punto se retoma un taller que hicimos con jóvenes de una institución educativa, en el barrio Champaquí, de Río Cuarto. En el marco de un ejercicio, propusimos un "buzón de dudas sobre violencia policial”, las cuales tenían carácter anónimo y eran respondidas colectivamente. Lo que atraviesa a todas las preguntas es el título de este acápite: ¿cuál es el mensaje que intenta transmitir la policía a través de la violencia? A continuación, se exponen solo algunas: 
¿Por qué algunos policías hacen lo que en realidad no tienen que hacer como dicen, por qué se meten con la droga si ellos arrestan y los castigan a los que se drogan, y por qué matan si están en contra de los que matan? (Joven, mujer, 18 de septiembre de 2019, Río Cuarto).

¿Por qué la policía tira tiros a la gente? ¿Por qué? (Joven, mujer, 18 de septiembre de 2019, Río Cuarto).

¿Por qué los policías disparan a la gente porque sí y en algunos casos acaban con sus vidas? (Joven, varón, 18 de septiembre de 2019, Río Cuarto).

¿Por qué la policía tiene más derechos que nosotros? (Joven, varón, 18 de septiembre de 2019, Río Cuarto).

Las preguntas precedentes evidencian la realidad compleja de los territorios habitados por los jóvenes, donde la violencia policial se despliega cotidianamente y cuyo mensaje no es aprehensible. ¿Por qué aceptar la violencia? ¿Cuál es el mensaje de esa violencia?

\section{Conclusiones}

En el presente artículo comprendimos la violencia policial desplegada sobre los jóvenes latinoamericanos como un mensaje, y fue abordada en dos ciudades latinoamericanas: Río Cuarto (Argentina) y Barranquilla (Colombia), por medio de los relatos de los jóvenes, víctimas de esas violencias. Como se indicó en el contexto conceptual, de todas las formas de violencia en este artículo nos ocupamos de la violencia policial, entendiendo que es el propio Estado el que a través de sus fuerzas de seguridad produce y perpetúa una violencia endémica de las sociedades.

En el desarrollo del trabajo se explicitaron primero algunos conceptos centrales que pusieron en contexto el abordaje teórico y el enfoque metodológico. Posteriormente se mostraron los indicadores globales de desarrollo humano en tensión con las tasas de homicidios de las ciudades objeto de estudio. Sin embargo, y a pesar de sus distancias geográficas y culturales, comprendimos que ambos escenarios de investigación comparten formas violentas de relacionamiento por las políticas de seguridad.

El emisor de la violencia policial, el agente de seguridad, despliega acciones de múltiples niveles de intensidad que tienen como destinatarios del mensaje a la propia institución policial, los vecinos, los familiares, otros jóvenes, militantes, hasta llegar al punto que funda la pregunta: ¿hacia quiénes va destinado el mensaje? ¿Por 
qué la crueldad de ese código, de este texto escrito con violencia artera? Tal como indicamos a través de Jobard, en la primera parte del trabajo, el uso policial de la fuerza tiene que ajustarse al ordenamiento jurídico, a la protección y al respeto de los derechos humanos. Sin embargo, el artículo aporta evidencias sobre el paradójico fenómeno al que recurren los países de la región tras la adhesión a los pactos que la Organización de las Naciones Unidas propone para el avance y la ampliación de derechos, y al mismo tiempo construye políticas públicas sustentadas en normativas que rompen esas convenciones y delegan a las fuerzas policiales la posibilidad de definir su aplicación mediante juicios más o menos ajustados al derecho, pero siempre sustentados en el olfato y la percepción. Se ponen en tensión bloques constitucionales garantistas y políticas de seguridad punitivistas, en el marco del avance de Estados penales (penalizados y penalizantes). Se suceden los gobiernos, pero las prácticas policiales y sus respectivas orientaciones políticas proponen como respuesta el control del territorio a través de las detenciones, que habilitan las situaciones de violencia aquí descritas y analizadas.

Resulta urgente repensar la "seguridad" en tanto protección de todas las personas y de las condiciones para la garantía del ejercicio de sus derechos. En este sentido, es urgente construir políticas de seguridad que interpelen las prácticas actuales, que reservan la noción de seguridad exclusivamente a la prevención y persecución de delitos callejeros y al miedo a ser víctimas de esos delitos. No aparece como relevante la seguridad jurídica, un marco de garantías mínimo y razonable para quienes son blanco policial, en estas condiciones y entornos. Para representar y problematizar estas temáticas es necesario el cese de la violencia que se advierte durante el trabajo de campo. Los Estados deben atravesar procesos de liderazgo de formas de relacionamiento no violentos para avanzar hacia la reducción de la violencia en los órdenes familiar, escolar o comunitario. No obstante, mientras los Estados ejerzan las tradicionales funciones de control y represión del delito, a través de la persecución de los jóvenes de sectores populares, cuyas vidas se proyectan en condiciones precariedad material, será sumamente complejo reducir las conflictividades en otros órdenes y el juvenicidio se consolidará en la región.

En este escenario complejo y contradictorio transcurren las vidas de jóvenes cuyas familias son poblaciones excluidas. Estas prácticas de violencia solo ahondan brechas en cuanto a derechos, aquellos que históricamente le son negados. No solo viven en casas precarias con hacinamiento, barrios oscuros y sin condiciones de salubridad, sino que además se le suma esta segunda condición a la que son vulnerables: los jóvenes son perseguidos justamente porque provienen de aquellos sectores 
que el Estado no prioriza en términos de aseguramiento de derechos. Es necesario construir proyectos que incluyan a los jóvenes, entendiendo que sus vidas deben transcurrir en escenarios más justos e igualitarios. Estos jóvenes, biológicos, históricos y sociales, pero sobre todo como indicó Filardo, jóvenes cuya edad burocrática es el criterio que prima en las políticas públicas, necesitan pensar en horizontes de reducción de las desigualdades, con un Estado que esté presente no para perseguirlos y violentarlos, sino para confirmar los derechos que detentan por ser ciudadanas y ciudadanos de nuestros países.

\section{Sobre la autora}

Mariana Jésica Lerchundi. Es licenciada en Ciencia Política de la Universidad Nacional de Río Cuarto (UNRC) y doctora en Administración y Política Pública de la Universidad Nacional de Córdoba, institución en la que también cursó el programa multidisciplinar de Posdoctorado en Ciencias Sociales, Ciencias de la Comunicación, Humanidades y Artes. Es vicecoordinadora de la Licenciatura en Ciencia Política y profesora concursada en Teoría Política I de la UnRC y Becaria de Conicet-Argentina. Sus artículos más recientes son: "Políticas de seguridad y configuraciones subjetivas en jóvenes de sectores populares (Argentina)" (2019); "Precariedad y desarrollo social. Conflictividad multiagencial en jóvenes de sectores populares (Río Cuarto, Argentina)” (2019); “La captura policial a la población joven: dimensiones jurídicas y experienciales en Río Cuarto de Argentina (2003-2015)" (2019). Estos escritos se publicaron en revistas de México, Cuba y Colombia, respectivamente. Es autora del capítulo "Política de seguridad y prácticas de interceptación policial en sociedades desiguales. Experiencias de jóvenes de Colombia y Argentina”, en el libro Las desigualdades en clave generacional hoy: las juventudes y las infancias en el escenario latinoamericano y caribeño, compilado junto con Liliana Mayer y María Isabel Domínguez (Clacso, 2020).

\section{Referencias}

Alcaldía de Barranquilla. (2019). Unidad de Servicios en Convivencia y Justicia -UCJ-ya está prestando servicios en sus nuevas instalaciones. Recuperado de https://www.barranquilla.gov. co/seguridad/unidad-de-servicios-en-convivencia-y-justicia-ucj-ya-esta-prestandoservicios-en-sus-nuevas-instalaciones

Alpízar, L. y Bernal, M. (2003). La construcción social de las juventudes. Última Década, 19(1), 105-123. Recuperado de http://www.scielo.cl/pdf/udecada/v11n19/art08.pdf 
Asamblea General de las Naciones Unidas. (1948). Convención para la Prevención y la Sanción del Delito de Genocidio. Recuperado de http://www.senado.gov.ar/bundles/senadoparlamentario/pdf/70/con-prev-san-genocidio.pdf

Bailone, M. (2016). Genocidio, jurisdicción universal y criminología cautelar. Derecho Penaly Criminología, 6(5), 63-72.

Balardini, S. (2000). De los jóvenes, la juventud y las políticas de la juventud. Última Década, 13(1), 11-24. Recuperado de http://www.scielo.cl/pdf/udecada/v8n13/art02.pdf

Barzola, M. (2016). "Vagos y Malentretenidos”: la vigencia de un estereotipo en el sur de Córdoba (1850). En Actas XXI Jornadas Internacionales Interdisciplinarias de la Fundación Icala sobre "Ética en la ciencia y en la vida" (pp. 184-187). Río Cuarto: Ediciones del Icala.

Binder, A. y Martínez, J. (1998). Informe Regional: Mecanismos de Control Democrático en el Mantenimiento de la Seguridad Interior. Control democrático en el mantenimiento de la seguridad interior (pp. 45-68). Santiago de Chile: CED.

Bittner, E. (1970). The functions of the police in modern society: a review of background factors, current practices, and possible role models. Chevy Chase, MD: National Institute of Mental Health Center for Studies of Crime and Delinquency.

Bittner, E. (1974). Florence nightingale in pursuit of willie sutton: a theory of the police. The Potential for Reform of Criminal Justice, 3(1) 233-68.

Bourdieu, P. (2002). La "juventud” no es más que una palabra. Sociología y cultura (pp. 163173). México: Conaculta.

Brodeur, J. (2011). Las caras de la policía. Buenos Aires: Prometeo.

Comisión Interamericana de Derechos Humanos. (2015). Violencia, niñez y crimen organizado. OEA. Recuperado de http://www.oas.org/es/cidh/informes/pdfs/ViolenciaNinez2016.pdf

Cozzi, E. (2016). De juntas, clanes y broncas: regulaciones de la violencia altamente lesiva entre jóvenes de sectores populares en dos barrios de la ciudad de Santa Fe. Delito y Sociedad, 39(24), 72-102.

Dammert, L. (2003). Participación comunitaria en la prevención del delito en América Latina. ¿De qué participación hablamos? Santiago de Chile: Centro de estudios de Desarrollo.

Dammert, L. (2005). Reforma policial en América Latina. Quórum, Revista Iberoamericana, $12(1), 53-64$.

Duarte Quapper, C. (2000). ¿Juventud o juventudes? Acerca de cómo mirar y remirar a las juventudes de nuestro continente. Última Década, 13(1), 59-77. Recuperado de http://www. redalyc.org/articulo.oa?id=19501303

El Colef. (s. f.). Convoca El Colef a Diplomado "Juvenicidio y vidas precarias en América Latina". Recuperado de goo.gl/vRDXG7

Feffermann, M. (2015). Genocidio de la Juventud Negra: deconstruyendo mitos. En J. M. Valenzuela (Coord.), Juvenicidio: Ayotzinapa y las vidas precarias en América Latina (pp. 165 196). México: Ned Ediciones-El Colegio de la Frontera Norte-Iteso. 
La violencia policial como "mensaje": un abordaje desde la experiencia...

Filardo, V. (2018). Juventud, juventudes, jóvenes: esas palabras. Última Década, 26(50), 109-123.

Flick, U. (2007). Introducción a la investigación cualitativa. Madrid: Morata.

Frederic, S. (2009). Los usos de la fuerza pública. Debates sobre militares y policías en las ciencias sociales de la democracia. Los Polvorines, Argentina: Universidad Nacional de General Sarmiento.

Galvani, M. (2007). La marca de la gorra. Un análisis de la Policía Federal. Buenos Aires: Capital Intelectual.

García Pulgarín, A. (2012). Prevención situacional y control de los espacios públicos. Revisión de algunos modelos teóricos a propósito del contexto colombiano. Revista Electrónica, Facultad de Derecho y Ciencias Politicas, 8(3), 3-18.

Garriga Zucal, J. (2016). Los sinsabores del verdadero policía. Representaciones laborales y legitimidad de la violencia policial. Primera Revista Electrónica en Iberoamérica Especializada en Comunicación, 93(1), 724-742.

Garriga Zucal, J. y Melotto, M. (2013). La diversidad (in)visible. Identidad(es) entre policías bonaerenses. Avá, 22(1), 77-96. Recuperado de http://cort.as/-K7_q

Gramsci, A. (1981). Cuadernos de la cárcel. México: Era.

Guba, E., y Lincoln, Y. (1994). Paradigmas en pugna en la investigación cualitativa. Handbook of Qualitative Research (pp.105-117). Londres: Sage.

Hopenhayn, M. (2007). Participación juvenil y política pública: un modelo para armar. En: Congreso Latinoamericano y Caribeño de Ciencias Sociales de FLACSO, 50 años. Recuperado de http://www.eclac.org/dds/noticias/paginas/8/37518/presentacion-MartinHopenhayn.pdf

Jobard, F. (2018). Violencia policial. Entre soberanía y contingencia. En Democracia y F. Trautmann (Ed.), Os protegemos de vosotros mismos. La política policial (pp. 129-135). Brumaria: Hal.

Krauskopf, D. (2019). Relaciones intergeneracionales, emancipación e independencia de jóvenes estudiantes chilenos. Revista Latinoamericana de Ciencias Sociales, Niñez y Juventud, $17(1), 75-88$.

Lerchundi, M. (2015). Comprensiones de juventud(es) y políticas públicas. Algunos abordajes posibles. Sociedad, Actores y Conocimiento: Contribuciones desde la Diversidad, 8(1), 201-218.

Lerchundi, M. (2018). Las prácticas de interceptación policial como primer eslabón de la cadena punitiva. Revista Kairos, 22(41), 1-28. Recuperado de https://www.revistakairos.org/laspracticas-de-interceptacion-policial-como-primer-eslabon-de-la-cadena-punitiva/

Lerchundi, M. (2019). Precariedad y desarrollo social. Conflictividad multiagencial en jóvenes de sectores populares (Río Cuarto, Argentina). Estudios del Desarrollo Social: Cuba y América Latina, 7(1), 22-44. 
Lerchundi, M. y Bonvillani, A. (2014). Jóvenes y Código de Faltas. Una 'experiencia’ de detención. Justicia Juris, 10(1), 43-52.

Llobet, V. (2015). Políticas y violencias en clave generacional en Argentina. En J. M. Valenzuela (Coord.), Juvenicidio: Ayotzinapa y las vidas precarias en América Latina (pp. 215-235). México: Ned Ediciones-El Colegio de la Frontera Norte-Iteso.

López, A., Guemureman, S. y Bouilly, M. (2012). El Estado de los datos. La dificultad de conocer. En A. Daroqui, A. L. López y Cipriano R. F. (Coord.), Sujetos de castigos. Hacia una sociología de la penalidad juvenil (pp. 61-84). Rosario: Homo Sapiens Ediciones.

Manning, M. (2011). Contingencias policiales. Buenos Aires: Prometeo.

Manning, P. (1991). Aspects of police work by Egon Bittner. Contemporary Sociology, 20(3), 435-436.

Marx, K. (2014). El Capital. México: Fondo de Cultura Económica.

Monjardet, D. (2010). Lo que hace la policía. Sociología de la fuerza pública. Buenos Aires: Prometeo.

Nateras, A. (2015). El aniquilamiento identitario infanto-juvenil en Centroamérica: el caso de La Mara Salvatrucha (MS-13), y la 'pandilla' del Barrio 18 (B-18). En J. M. Valenzuela (Coord.), Juvenicidio: Ayotzinapa y las vidas precarias en América Latina (pp. 99-130). México: Ned Ediciones-El Colegio de la Frontera Norte-Iteso.

Navarro, D. y Pérez, J. M. (14 de enero de 2019). Homicidios bajaron en Atlántico y Barranqui1la. El Heraldo. Recuperado de https://www.elheraldo.co/judicial/homicidios-bajaronen-atlantico-y-barranquilla-587995

Oficina de Naciones Unidos contra la Drogra y el Delito. (2019). Global study on homicide. Nueva York. Recuperado de https://www.unodc.org/documents/data-and-analysis/gsh/ Booklet1.pdf

Pita, M. (2017). Pensar la violencia institucional. Vox populi y categoría política local. Espacios de Crítica y Producción, 53(1). 25-32.

Programa de las Naciones Unidas para el Desarrollo. (2014). Informe Regional de Desarrollo Humano 2013-2014. Seguridad ciudadana con rostro humano: diagnóstico y propuestas para América Latina. Estados Unidos. Recuperado de https://www.undp.org/content/dam/ rblac/img/IDH/IDH-AL\%2OInforme\%2Ocompleto.pdf

Programa de Naciones Unidas para el Desarrollo. (2019). Panorama general. Informe sobre Desarrollo Humano 2019. Más allá del ingreso, más allá de los promedios, más allá del presente: Desigualdades del desarrollo humano en el siglo ххг. Nueva York. Recuperado de http://hdr. undp.org/sites/default/files/hdr_2019_overview_-_spanish.pdf

Rangel, L.y Alves, R. (2015). Los jóvenes que más mueren: los negros y los indígenas en Brasil. En J. M. Valenzuela (Coord.), Juvenicidio: Ayotzinapa y las vidas precarias en América Latina (pp. 197-214). México: Ned Ediciones-El Colegio de la Frontera Norte-iteso.

Reguillo, R. (2012). Culturas juveniles: formas políticas del desencanto. Buenos Aires: Siglo XXI Editores. 
Reguillo, R. (2013). Jóvenes en la encrucijada contemporánea: en busca de un relato de futuro. Debate Feminista, 48(1), 137-154.

Saín, M. (1998). Democracia, seguridad pública y policía. La reforma del sistema .de seguridad y policial en la Provincia de Buenos Aires. En Las reformas policiales en Argentina (pp. 68105. Buenos Aires: CELS.

Saín, M. (2008). El Leviatán azul. Policía y política en la Argentina. Buenos Aires: Siglo XXI Editores.

Sautu, R. (2003). Todo es teoría. Objetivos y métodos de investigación. Buenos Aires: Lumiere.

Segato, R. (2016). La guerra contra las mujeres. España: Traficantes de Sueños.

Seguezzo, G. (2010). La construcción de la 'violencia policial' en las ciencias sociales: entre los derechos humanos y la inseguridad. $V$ Jornadas de Sociología de la UNLP. Universidad Nacional de La Plata. Facultad de Humanidades y Ciencias de la Educación. Departamento de Sociología, La Plata.

Sirimarco, M. (2009). De civil a policía. Una etnografía del proceso de incorporación a la institución policial. Buenos Aires: Teseo.

Skolnick, J. (1965). Justice without trial. Nueva York: Wiley.

Skolnick, J. y Fyfe, J. (1993). Above the law. Nueva York: The Free Press.

Sozzo, M. (2000). ¿Hacia la superación de la táctica de la sospecha? Notas sobre prevención del delito e institución policial. En Detenciones, facultades y prácticas policiales en la ciudad de Buenos Aires (pp. 3-41). Buenos Aires: CELS/CET.

Telediario.com.ar. (2 de diciembre de 2019). 2019 violento en Río Cuarto: 14 crímenes en menos de un año. Recuperado de https://www.telediariodigital.net/2019/12/2019-violento-enrio-cuarto-14-crimenes-en-menos-de-un-ano/

Tiscornia, S. (2000). Seguridad y cultura de la violencia: El teatro de la furia. Encrucijadas, 1(1), 49-59.

Tiscornia, S. (2017). La violencia institucional como tema de trabajo e investigación. Una breve historia. Espacios de Crítica y Producción, 53(1) 25-32.

Tiscornia, S. (Comp.). (2004). Burocracias y violencia. Estudios de antropología política. Buenos Aires: Antropofagia.

Valenzuela Arce, J. M. (2012). Sed de mal: feminicidio, jóvenes y exclusión social. México: El Colegio de la Frontera Norte-Universidad Autónoma de Nuevo León.

Valenzuela Arce, J. M. (2015). Remolinos de viento: juvenicidio e identidades desacreditadas. En J. M. Valenzuela (Coord.), Juvenicidio: Ayotzinapa y las vidas precarias en América Lati$n a$ (pp. 15-58). México: Ned Ediciones-El Colegio de la Frontera Norte-iteso.

Valenzuela Arce, J. M. (2019). Trazos de sangre y fuego. Alemania: Calas.

Valenzuela Arce, J. M. y Morañas, M. (Coord.) (2017). Precariedades, exclusiones y emergencias. México: Gedisa. 
Valles, M. S. (1999). Técnicas cualitativas de Investigación Social: reflexión metodológica y práctica profesional. Madrid: Síntesis.

Vargas Velásquez, A. (Coord.). (2012). El prisma de las seguridades en América Latina. Escenarios regionales y locales. Buenos Aires: Clacso.

Wacquant, L. (2004). Las cárceles de la miseria. Manantial, Buenos Aires.

Waldmann, P. (2003). El Estado anómico: derecho, seguridad pública y vida cotidiana en América Latina. Caracas: Nueva Sociedad.

Zaffaroni, E. (2012). Crímenes de Masa. Buenos Aires: Ediciones Madres de Plaza de Mayo. 